


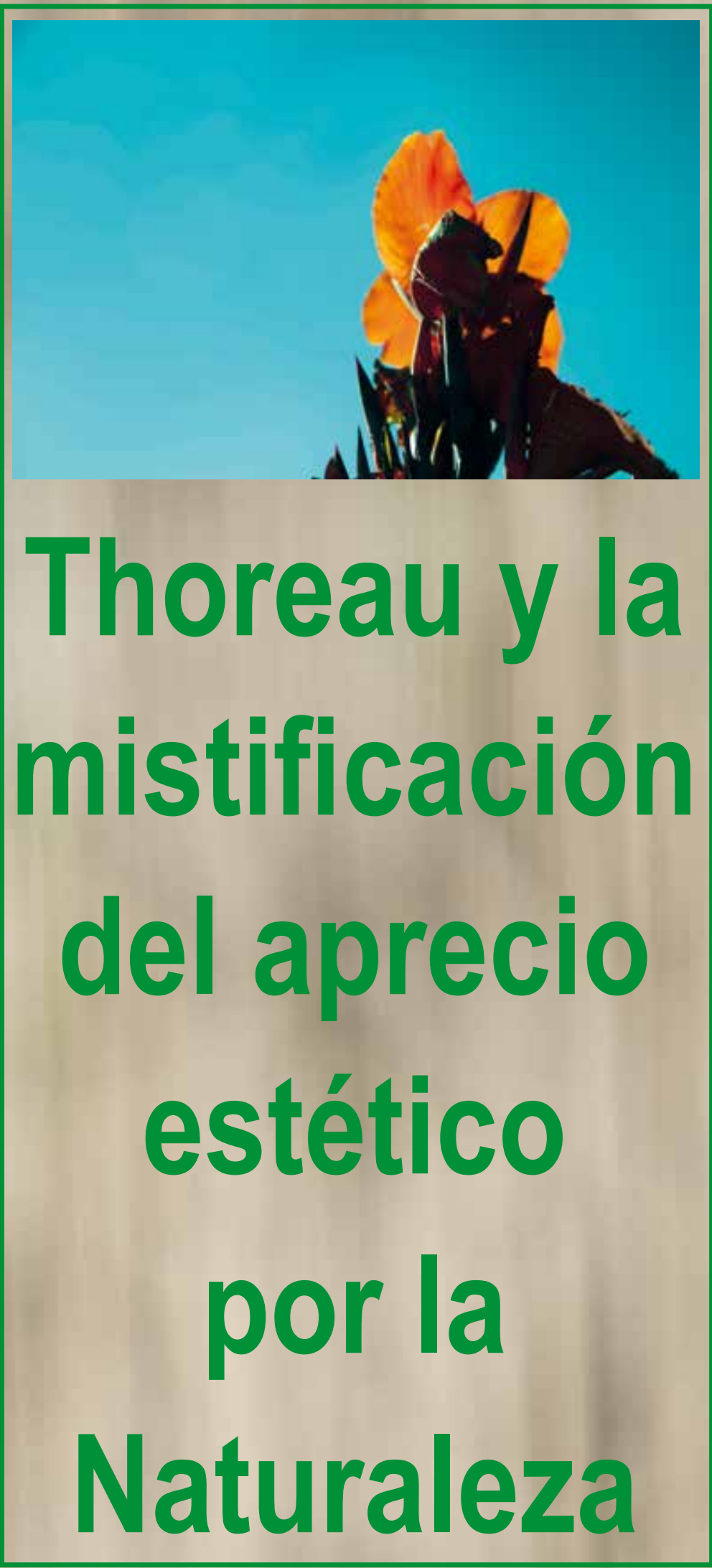

Javier Guillermo Merchán-Basabe 


\section{Thoreau y la mistificación del aprecio estético por la Naturaleza`}

Veo, huelo, gusto, oigo ese Algo al que estamos unidos y que es al mismo tiempo nuestro hacedor, nuestra morada, nuestro destino y nosotros mismos; la única verdad histórica, el hecho más notable que puede ser el tema preciso y no solicitado de nuestro pensamiento, la verdadera gloria del universo, el único hecho que un ser humano no puede dejar de reconocer ni en cierto modo olvidar, ni del cual puede prescindir.

Thoreau, Diario íntimo (Dreiser; 1980, p. 76)

\section{Resumen}

Este trabajo hace un estudio del aprecio estético por la Naturaleza en Henry David Thoreau con miras a exponer sus consecuencias prácticas. Analiza así su acepción de la experiencia de la belleza salvaje, su distancia de la belleza del arte y su concepción de la Naturaleza como modelo moral.

Palabras clave: naturaleza, belleza salvaje, mistificación-racionalización, belleza natural

\section{Thoreau and the Mystification of Aesthetic Appreciation of Nature}

\section{Abstract}

This paper studies aesthetic appreciation of Nature in Henry David Thoreau, seeking to reveal its practical consequences. We analyze his sense of the experience of wild beauty, his distance from the beauty of art, and his conception of Nature as a moral model.

Keywords: nature, wild beauty, mystification-rationalization, natural beauty

\section{Thoreau e a mistificação do aprecio estético pela Natureza}

\section{Resumo}

Este trabalho realiza um estudo do aprecio estético pela natureza segundo Henry David Thoreau, visando expor suas consequências práticas. Analisa-se sua acepção da experiência da beleza selvagem, sua distância da beleza da arte e sua concepção da Natureza como modelo moral.

Palavras chave: natureza; beleza selvagem; mistificação-racionalização; beleza natural

1 Este artículo es un pequeño extracto de una obra que planea ser titulada Ensayos sobre estética de la Naturaleza y que se encuentra en proceso de elaboración, como parte de un proyecto de investigación del Departamento de Filosofía de la Universidad Pedagógica Nacional. 


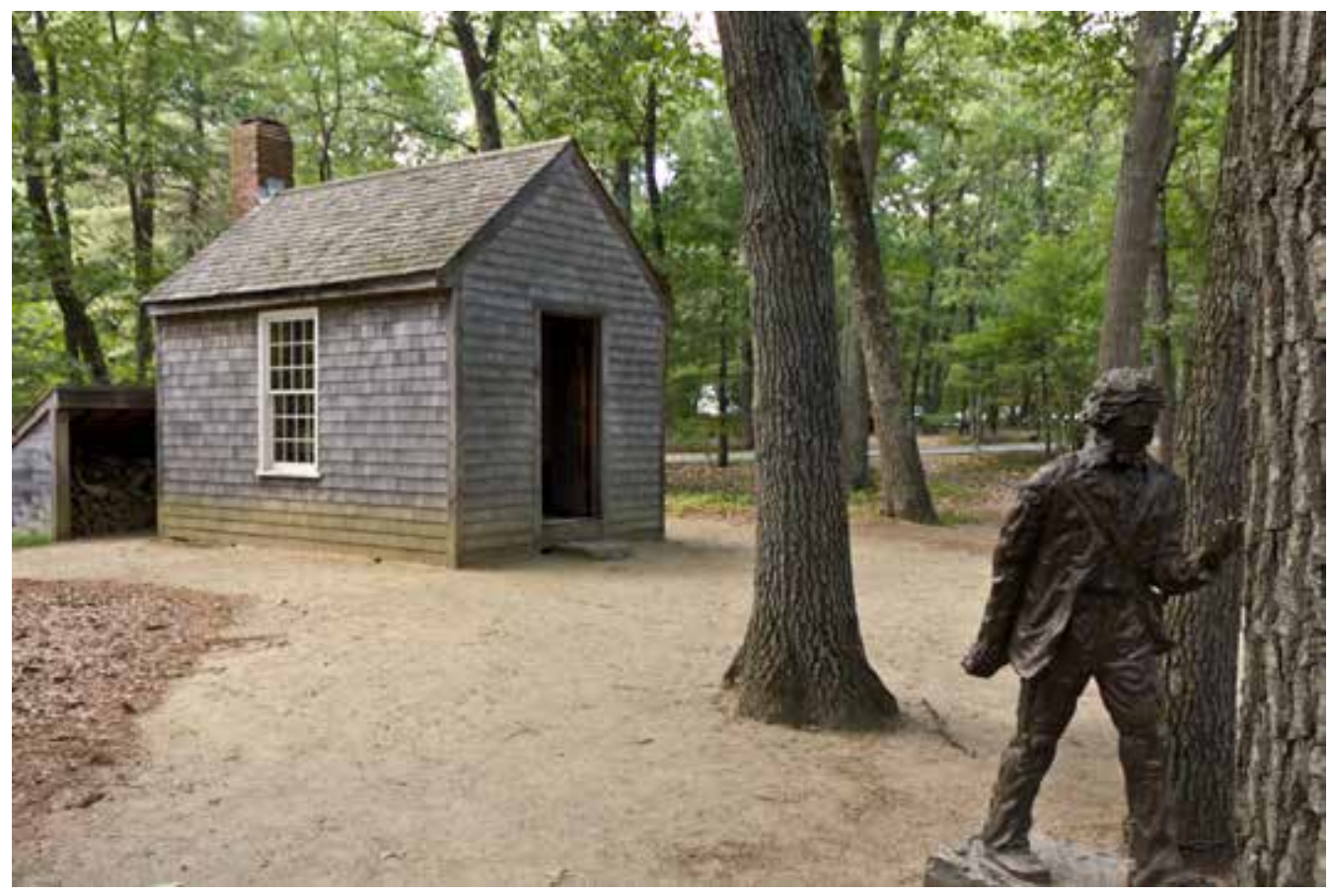

Figura 1.Tomado de: https://commons.wikimedia.org/wiki/ File\%3AReplica_of_Thoreau's_cabin_near_Walden_Pond_and_ his_statue.jpg

La consolidación de la revolución industrial de Estados Unidos, de hecho la consolidación de Estados Unidos como nación continental fue producto de la actitud expansiva hacia los espacios de naturaleza intocada. Las necesidades propias de una sociedad en camino de industrialización convirtieron la Naturaleza en una promesa de felicidad, en una cosa apta para la posesión de sus riquezas, hasta el momento desaprovechadas, pero dispuestas para quien se arriesgase a tomarlas. La guerra contra los nativos por el dominio de sus territorios, la fiebre de oro, de hierro, de acero, de carbón, de pieles, la colonización de espacios para ganadería y la agricultura, la expansión de medios de comunicación, la construcción de ferrocarriles, el correo, la emergencia de nuevas y opulentas ciudades, la generación de marcos jurídicos para la titulación de terrenos, de reservas, etc., son todos síntomas de la cristalización de dicha promesa.

Hacia la segunda mitad del siglo xIx la concepción de la Naturaleza se vio trastocada frente a la progresiva secularización del pensamiento; nuevas condiciones espirituales surgieron ante un retroceso del calvinismo, del puritanismo conservador y otras doctrinas como el unitarismo, que, en general, se alejaban de la búsqueda de explicaciones concretas de la realidad, y primaron entonces especulaciones centradas en la interpretación de los dogmas. Justamente el acercamiento utilitarista de la sociedad preindustrial a la Naturaleza no dejaba de estar fundado en una crítica de la influencia teológica-moral, herencia de la tradición protestante, que veía en los espacios naturales algo digno de rechazo. Frente a estas nuevas condiciones espirituales, la búsqueda de concreción de la promesa de felicidad conllevó a la generación de una sensibilidad distinta fundamentada en mitologías modernas como las de Naturaleza pura, intocada, totalidad pródiga e indómita, etc., lo cual estaba profundamente asociado al imaginario colectivo de la belleza salvaje, que exaltaba el carácter indomable, desconocido y dadivoso de la Naturaleza, contrapuesto a la libertad de tomar lo deseado o preservarlo.

En este panorama se dio el trascendentalismo americano, un movimiento intelectual $^{2}$ que adoptó ciertas ideas del Romanticismo europeo (Kant, Goethe, Coleridge, Worsdworth), las cuales reemplazaban una visión mecánica de la Naturaleza por la de un organismo cambiante. Los trascendentalistas vindicaban la unidad de toda la creación, la concepción de la intuición, la contemplación y el sentimiento como formas de revelación superior a la razón, la idea de un espíritu o inteligencia universal, la crítica de los criterios de veracidad en la filosofía, entre otros. Un importante filósofo de la época, Ralph Aldo Emerson, sacerdote unitarista, escribió el "Ensayo sobre la Naturaleza", un texto que tiene cierta relevancia a la hora de exponer unos criterios que suelen asociarse a la visión de los trascendentalistas. En términos generales, Emerson hace una crítica de la razón como forma primada de conocimiento, se vale del concepto de fuerza vital o Dios y señala que, como tal, está en todas partes, y no puede ser subsumida en el pensamiento, de tal manera se evidencia que la Naturaleza no es estática sino fluida, y el espíritu es quien la modifica; ella se desdobla en particularidades que dan cuenta de una esencia única y que no puede ser alcanzada por mediaciones teológicas o filosóficas, sino trascendiendo lo material. En consecuencia, no puede subordinarse la Naturaleza a la ciencia pues el espíritu está presente en ella, no constituye la Naturaleza externamente 0 en derredor nuestro, sino a través de nosotros, pues los hechos naturales son símbolos de hechos espirituales. En ese sentido, la filosofía de Emerson es asociada a cierto tipo de vitalismo que pretende vindicar la experiencia de la Naturaleza como forma de conocer sus leyes y funciones, resultado de aproximar la sensibilidad al espíritu, ya que la Naturaleza es asimilada a creación, lo divino es inmanente, y su verdad está dada en una revelación inmediata, en una intuición. De tal forma, para Emerson la Naturaleza resulta un símbolo vívido para llegar al espíritu; ella, en toda su extensión, es un medio, una única vía para pensar el absoluto, el orden y el diseño de la creación.

2 Tal vez sus principales representantes son Emerson, Hawthorne, Longfellow, Alcott y Carlyle, entre otros. 
El acercamiento de los trascendentalistas a la Naturaleza no estuvo alejado de las formas tradicionales del panteísmo, ese tipo pensamiento que con pretensión de superar el dualismo asumía que Dios era principio del mundo orgánico. Para ello se valían de una tendencia de unir lo particular a lo universal, la materia al espíritu, y postularon la unidad de la creación como algo que se revelaba en la intuición, una forma trascendente de conocimiento que, sin embargo, no era asociada a la experiencia estética. En lo que tocaba al aprecio estético por la Naturaleza por parte de los trascendentalistas, la figura más representativa vendría a ser Henry David Thoreau. Thoreau planteó un tipo de apreciación estética de la Naturaleza que hoy, sobretodo, cobra vigencia: la promoción de una relación no utilitaria con la Tierra. Entre sus reflexiones, contenidas a lo largo de múltiples diarios y publicaciones, resaltan: la experiencia de la belleza salvaje como reconocimiento de la fuerza vital y primigenia, la concreción de la experiencia estética desde un tipo particular de intuicióncontemplación y la concepción de la Naturaleza como el modelo para el arte y la vida práctica.

Puede decirse que el pensamiento estético de Thoreau apuesta por una mistificación de la Naturaleza, por una concepción que remite un sentido mistérico, al desconocimiento de su ser ${ }^{3}$. La mistificación de la Naturaleza se funda en la crítica de la aspiración racional de contenerla, en la búsqueda de la posibilidad de encontrarse su esencia desde la vivencia, no tanto en un intento por vindicar algún carácter religioso, sagrado y esotérico, sino en la exhortación al reconocimiento de la experiencia estética como belleza dada para reconocimiento del ser en sí de la Naturaleza. De tal forma, Thoreau promueve no un reconocimiento intelectual ni utilitario de la Naturaleza, sino, más bien, la interiorización del valor de sus principios, pues lo oculto no se resuelve en la representación psicológica, filosófica 0 científica, sino en su apreciación trascendente.

En este panorama, la mistificación de la Naturaleza antepone una crítica de las formas de conocimiento, y de los fundamentos y métodos de la ciencia ${ }^{4}$. La ciencia no propicia el reconocimiento de un ser que se describe según su mecánica ${ }^{5}$, ella no deja entrever el todo, ya que la información técnica, la especialización o los números, hacen perder de vista una totalidad que es ajena a la taxonomía, como resulta en el caso del estudio del hombre o la vida. La ciencia natural aporta datos, pero los datos no alcanzan para suponer el origen de la Naturaleza, su fuerza, su perfección, ni sus leyes; la ciencia no hace al hombre reconocer a la Tierra como un organismo vivo ${ }^{6}$. De tal forma, el acercamiento a una Naturaleza mistificada requiere de un pensamiento poiético que

3 "No sé dónde encontrar en cualquier literatura, sea antigua o moderna, una explicación adecuada de la Naturaleza que conozco. La mitología es la que más se acerca a esa explicación" (Dreiser, 1960: 81).

4 "Toda ciencia no es más que provisional, un medio para un fin que nunca es alcanzado, toda descripción es propuesta hasta que conocemos el todo, pero entonces la ciencia es dejada de lado" (Dreiser; 1960: 89).

5 "Nuestra ciencia, llamada así, es siempre más estéril y está más impurificada por el error que nuestras simpatías" (Dreiser; 1980: 92).

6 "La tierra que piso no es una masa muerta e inerte, es un cuerpo, tiene un alma, es orgánica. Son ilimitadas las finas entrañas que nos muestra" (Dreiser; 1980: 69). sea capaz de equilibrar el impulso de las formas abstraccionistas del pensamiento racional, sin eclipsarlas, pues, aunque la ciencia resulta un acercamiento técnico a las cosas y no revela la esencia de estas, el valerse de datos y desarrollar teorías sirve para ilustrar la experiencia de un misterio ${ }^{7}$. La descripción naturalista es también una contribución para la filosofía, los datos importan, no por el cómo se organizan, sino por qué y para qué se organizan con respecto al cuestionamiento por la vida en general ${ }^{8}$.

En la reflexión de Thoreau no se puede evidenciar ni criticar una teoría o un concepto delimitado, tal vez un método; Thoreau busca por medio de la poesía ${ }^{9}$ la actividad física y la descripción de datos que arrojan investigaciones desde experiencias inmediatas, un acercamiento simbólico y a la vez concreto a la Naturaleza ${ }^{10}$. No hay un sistema a priori, menos una acepción previa de la experiencia estética de la Naturaleza, no hay una teoría o concepto unificado de la Naturaleza, sino la eterna búsqueda de un misterio que se presenta desde un hecho particular para hacer inferir la totalidad. El proceder del pensamiento reconoce las actividades materiales de la Naturaleza, que luego son transgredidas en sus límites sensibles y representacionales, todo para esbozar los caracteres de un principio absoluto ${ }^{11}$. Por ello, como naturalista, Thoreau no centra el interés en los fenómenos y leyes científicas generales, sino en las explicaciones sobre variaciones de un prototipo que funciona localmente con respecto a la generalidad; su atención está en la función particular de un ser vivo en un ecosistema, y lo está para tratar de fondo principios estéticos como el cambio y la fuerza vital ${ }^{12}$, anima en la Naturaleza ${ }^{13}$. En esa medida, se da la reconcepción de la historia natural tradicional, la cual supone que la investigación sobre las plantas y los animales requiere atentas observaciones, pero no para determinar leyes medibles por datos tomados de experimentaciones, pues no se busca una organización biológica o ley, sino la evidencia interna de un ente universal.

7 "La ciencia ha descubierto cambios gigantes en la superficie de la Tierra [...] no se ha producido una creación repentina, una nueva creación del mundo, sino un constante proceso según las leyes universales existentes" (Dreiser; 1980: 76).

8 "Si queréis conocer el helecho olvidad vuestra mecánica, para ese propósito no se necesita de ningún término, ni distinción científica, pues así tendréis el gusto de percibir algo que podréis acercar al objeto sin prejuicio alguno" (Dreiser; 1980: 90).

9 "[...] la poesía implica la verdad entera. La filosofía expresa una partícula de ella" (Dreiser; 1980: 178).

10 En vista de que este conocimiento de la Naturaleza se basa en la experiencia concreta, física, vivencial y subjetiva, se requiere de la observación, un agudo carácter descriptivo y un pensamiento que se despliega desde la evocación poiética. Véase: "Una semana por los ríos de Concord y Marrimale" (Thoreau, 2004), un poema en prosa rendido al aprecio por la Naturaleza, a la vez que una descriptiva minuciosa de las formas materiales y de las maneras en que la percepción y los sentidos son trascendidos para develar un principio superior.

11 "Estamos relacionados con toda la Naturaleza animada e inanimada y en consecuencia, compartimos hasta cierto punto lo propio de criaturas inactivas" (Dreiser; 1980: 71).

12 El cambio, la fuerza y el movimiento son principios de la Naturaleza que el hombre solo verifica estéticamente, la ciencia racionaliza la experiencia y abstrae de ella.

13 "La parte más importante de un animal es su ánimo. Su espíritu vital, en el que se basan su carácter y todas las particularidades que nos interesan en él. No obstante, la mayoría de los libros científicos que tratan de los animales prescinde de ello por completo y describe las cosas como fenómenos de una Naturaleza muerta" (Dreiser; 1980: 91). 
El método, pues, no se basa en la objetivación sino en la presentación poiética, esto es, en la descripción de acontecimientos que permiten inferir principios superiores, por ejemplo, el análisis naturalista que conlleva a un maravillamiento o sentimiento vivaz ante cosas de la Naturaleza, en el que se presenta libre de concepciones y fines humanos. La presentación poiética está mediada por la interacción ${ }^{14}$, la observación, por formas de la intuición y la contemplación que convocan sentimientos de autocercioramiento de nuestra comunión o distancia con respecto a la Naturaleza. Thoreau pareciera caracterizar la intuición estética: ella no es una forma racional de conocimiento, es una experiencia dada, en gran parte, como evidencia del orden superior del ser en sí de la Naturaleza; es mucho más que una apercepción convertida en representación objetiva ${ }^{15}$, es una forma de validar lo observado sin acotarlo, pero trascendido a una experiencia emocional o sentido de comunidad con el todo. La intuición estética es asimilada con algo inmediatamente dado que trasciende la mediatez del reconocimiento de los fenómenos, por ejemplo, la mediatez generada en la explicación de la ciencia y la teología $a^{16}$. Por otro lado, en varios apartados del Walden (2005), el estudio o el reconocimiento de los animales y sus interrelaciones propicia la caracterización de un tipo de contemplación ambulatoria y escindida del hombre sobre la Naturaleza, una forma de conocimiento en el que la emoción y la sensibilidad no son alejadas pero tampoco son la base de la experiencia. La contemplación estética convoca a asumir con el pensamiento que no estamos totalmente envueltos en Naturaleza, que solo nos reconocemos en la distancia ${ }^{17}$ como entidades humanas, como producto de la intelección sobre la vivencia, como alejamiento ${ }^{18}$. De la misma manera que la intuición estética, la contemplación estética no resulta una representación objetiva, antes bien es un estado de individuación ${ }^{19}$ en el que el acto de reparación en los detalles conlleva a notar que en cada uno de ellos se concentra la eternidad, que en cada especie se pone a los ojos, de forma sentida, el panorama crucial de la vida.

La Naturaleza mistificada supone estados de revelación y develamiento del ser en sí de esta. La sensibilidad o la intelección

14 "[...] el gusto por lo bello se cultiva al aire libre" (Dreiser; 1980: 41). Esto puede evidenciarse con la exaltación del deambular, andar o interactuar con espacios y seres naturales, por ejemplo, en el texto Caminar (Thoreau, 1998), que muestra que el aprecio por la belleza salvaje implica penetrar en la Naturaleza circundante.

15 "El misterio de la vida de las plantas está emparentado con el misterio de nuestras propias vidas, y el fisiólogo no debe suponer que puede explicar su desarrollo de acuerdo con leyes mecánicas como si pudiera explicar maquinaria que él mismo ha construido" (Dreiser; 1980: 87).

16 "Debéis ascender a la montaña para conocer nuestra relación con la materia y en consecuencia con vuestro cuerpo, pues él está allí, en su casa, aunque vosotros no lo estáis".

17 "Por intensa que sea mi experiencia, tengo consciencia de la presencia y de la crítica de una parte de mí mismo, que como la Naturaleza, no es una parte de mí mismo, sino un espectador" (Dreiser; 1980: 64).

18 "La Naturaleza soporta la inspiración más atenta. Nos invita a poner nuestros ojos a nivel de la hoja más pequeña y a tomar el insecto para examinarlo. Una extensión de agua revela el espíritu que hay en el aire, posee una nueva vida y movimiento, es intermediaria entre el cielo y la tierra" (Dreiser; 1980: 67). 19 "[...] con el pensamiento podemos colocarnos fuera de nosotros en un sano sentido. Mediante un esfuerzo consciente de la mente podemos permanecer apartados de los efectos de sus consecuencias todas las cosas buenas y malas pasan junto a nosotros como un torrente. No estamos completamente envueltos en Naturaleza" (Dreiser; 1980: 64). pueden proveer al individuo del reconocimiento de ciertos órdenes, por ejemplo a nivel visual. La intuición, por su parte, puede conllevar a la trascendencia de lo dado a la sensibilidad, por ejemplo del orden y jerarquía de ciertos elementos con respecto del todo. Sin embargo, solo la intuición y la contemplación estéticas pueden remitir al principio vivenciado del ser en sí de la Naturaleza que todo lo produce; solo en ese nivel se comprueba concretamente que la Naturaleza se extiende por todas partes como un organismo universal, que el hombre es miembro de ella y que está sometido a sus leyes universales ${ }^{20}$. Thoreau sustituye así la compulsión o necesidad interna de saber de la Naturaleza en un sentido abstracto, como el de Emerson o Hegel, por una reacción muy fina que hace al individuo evidenciar estéticamente la inteligencia y el orden de la Naturaleza, principios estéticos como el tiempo, el espacio, la forma y el cambio ${ }^{21}$. La belleza salvaje está en una intuición estética de comunión con la Naturaleza en la que ni la razón ni el individuo operan, pero también en su contraparte, en la contemplación estética, en un distanciamiento o individuación en que el pensamiento funda un alejamiento sentido. Así, puesto que no son dos formas de conocimiento totalmente separadas, contemplación e intuición estéticas, son instancias intermitentes para el reconocimiento de la belleza salvaje, una experiencia de la belleza de la Naturaleza que convoca el sentimiento de principios universales, un modelo para el arte y también una guía del papel del hombre en el mundo ${ }^{22}$.

Como crítico de la racionalización que convierte la Naturaleza en objeto, para Thoreau la belleza evoca un misterio ${ }^{23}$ que no puede ser simplemente aprehendido por la teoría. Thoreau asume que la belleza salvaje es una epifanía del ser en sí de la Naturaleza, una experiencia concreta devenida en reconocimiento de principios superiores, mucho más que el producto de un ejercicio intelectual ${ }^{24}$ que pretende vincularla a un sistema general de representación. En sus escritos, la Naturaleza primigenia, creadora y, al tiempo, destructora y agreste está ejemplificada en paisajes sentimentales, anímicos, a veces personificados, imágenes que en últimas quieren proyectarse al interior, a un hombre sensible entregado a los peligros y atractivos de la belleza salvaje. Thoreau no supone un paisaje delimitado por convenciones racionales previamente caracterizado bajo lineamientos artísticos, un espacio virgen o pintoresco mediado por las exigencias románticas de composición visual, sino todo lo contrario, no hay sistemas artísticos previos. Desde la intuición y contemplación estéticas, y el sentido de distancia y comunidad, la Naturaleza resulta bella y salvaje, eternamente destructora y creadora, artística, libre y regulada, fuerza espiritual que fundamenta la vida. Esa eterna creación-destrucción nos posibilita un devenir incesante de

20 "[...] estáis sujetos a la materia y al tiempo" (Dreiser; 1980: 123).

21 "Las cosas no cambian, somos nosotros los que cambiamos, ¿no está el mundo comenzando y terminando eternamente?" (Dreiser; 1980: 76).

22 "[...] el genio se inspira en sus propias obras, es hermafrodita, el antiguo universo es en ese sentido una riqueza capital y creo que indudablemente nunca morirá" (Dreiser; 1980: 79).

23 "El misterio de la vida de las plantas está emparentado con el misterio de nuestras propias vidas, y el fisiólogo no debe suponer que puede explicar su desarrollo de acuerdo con leyes mecánicas como si pudiera explicar maquinaria que él mismo ha construido" (Dreiser; 1980: 87).

24 "El único medio de decir la verdad es hablar amorosamente, únicamente son oídas las palabras de quien ama. El intelecto no debiera hablar nunca, no es sonido natural" (Dreiser; 1980: 80). 
experiencias que nos vivifican, algo que siempre trasciende nuestros límites para dar cuenta de la vida total o del genio constructivo que está presente en la Naturaleza. Por esto para Thoreau hay belleza tanto en la vida como en la destrucción y decadencia ${ }^{25}$, en cada rama, en cada hoja se prolonga la vida y la muerte, pues cada parte remite al todo, a la cambiante vitalidad primordial ${ }^{26}$. La belleza salvaje está por todas partes ${ }^{27}$, es inmanente a la Naturaleza; aunque la experiencia de la belleza sea íntima o personal, ella no es algo exclusivo de clases, estirpes o culturas, es algo revelado desde la interacción, algo inevitable ${ }^{28}$.

Dicha experiencia estética de la Naturaleza, como revelación momentánea del misterio de su ser en sí, hace que la belleza salvaje sea entendida como algo superior al arte ${ }^{29}$. La experiencia de la belleza natural es evidencia primaria del creador ${ }^{30}$, algo que el arte solo puede imitar mediado por la individuación de un artista $^{31}$. Él sabe que tal superioridad no es un impedimento; en la fluidez de la Naturaleza ${ }^{32}$ está el modelo del arte $^{33}$. Las mejores obras de arte se asimilan a la belleza salvaje ${ }^{34}$, resultan un acercamiento a la fuerza y vigor de la Naturaleza ${ }^{35}$. Si el arte es inferior a la belleza natural, no puede reemplazarla, menos copiarla; cualquier obra en la Naturaleza salvaje es muestra grandiosa de la inteligencia de un genio cuya exactitud y orden excede por mucho nuestra capacidad de entender o representar ${ }^{36}$. La existencia de un objeto natural devela

25 "Uno pudiera creer que las impurezas que colorean así la espuma pueden ser arregladas en formas tan agradables. Dadle cualquier material a la naturaleza y ella comenzará a darle formas agradables" (Dreiser; 1980: 68).

26 ¡Cuánta belleza hay en la decadencia!, tomo una hoja de roble seca y rígida, pero en la que todavía se mezclan el rojo y el verde, como en el mes de octubre, y cuya parte carnosa ha sido comida por un insecto" (Thoreau, 2005: 201).

27 "[...] esa es una belleza que existe, no aquí o allí, no en este momento 0 en el otro, no en Roma o en Atenas, sino dondequiera que haya un alma que la admire" (Dreiser; 1980: 176).

28 "El elogio de la aurora, por ejemplo, bajo alguna forma obedece en todas las épocas a un instinto tan irresistible como el que impele a las ranas a croar" (Dreiser; 1980: 78).

29 “¿Qué importan las joyerías? No hay nada más hermoso que un copo de nieve 0 una gota de rocío, terminados con la habilidad suprema del artista. [...] ¿Qué me importa ver galerías llenas de representaciones de dioses paganos si puedo ver los naturales y vivientes creados por un artista infinitamente superior sin un telescopio? (Dreiser; 1980: 69).

30 Aunque resulta reconocido y aceptado que Thoreau defiende cierto ateísmo naturalista, crítico de la religión y la teología, en muchas partes aparece como un panteísta y se asume como parte orgánica del todo y sus principios. En uno u otro caso es reconocido por Thoreau un orden y principios superiores que no obedecen a una causa material sino trascendental, en ese sentido usa la palabra creador, como orden divino.

31 "¡Qué me importa ver galerías llenas de representaciones de dioses paganos si puedo ver los naturales y vivientes, creados por un artista infinitamente superior, sin un telescopio?" (Dreiser; 1980: 71).

32 "El arte no puede nunca cumplir con la super-fluidad de la Naturaleza. El verdadero arte no es más que nuestra expresión de amor por la Naturaleza" (Dreiser; 1980: 179).

33 "No tiene importancia que el poeta diga una cosa particular, sino que la diga en armonía con la Naturaleza" (Dreiser; 1980: 181).

34 "Un hombre que escribe es el amanuense de la Naturaleza entera, es el trigo y la hierba, y la atmósfera que escriben" (Dreiser; 1980: 178).

35 "La obra de arte perfecta es recibida de nuevo en el seno de la Naturaleza de donde procede su material y la crítica no puede hacer otra cosa que reconocer su propia falta de naturalidad" (Dreiser; 1980: 179).

36 "[...] todos esos sonidos, el cacareo de los gallos, el ladrido de los perros, el zumbido de los insectos al medio día, son la prueba de la riqueza o del estado sonoro de la Naturaleza. Tales son la belleza y la exactitud [...] el arte más perfecto del mundo" (Dreiser; 1980: 181). la necesidad de este como elemento compositivo de un todo ${ }^{37}$, no como un accidente azaroso, aunque aparentemente lo sea, sino como parte minúscula, pero indispensable, en el actual estado de devenir de la Naturaleza según su principio superior ${ }^{38}$. El arte solo puede ser el producto del reconocimiento de la belleza salvaje, la conciencia del misterio de la Naturaleza y el ímpetu impasible por el develamiento y la revelación de su ser en sí. Para Thoreau resulta monstruoso que el hombre haya llegado a la instancia de primar el arte sobre la Naturaleza ${ }^{39}$, ya que, para él, el sentido por lo determinable, por lo medible y útil es solo una solapada manera de artificialidad.

La exaltación de la belleza salvaje no es solo para evidenciar el modelo para el arte, sino para la moral; en últimas, frente a la belleza salvaje, es el hombre quien termina reconociéndose ${ }^{40}$. La síntesis de todo dualismo, materia-espíritu, Naturaleza-razón, es el cercioramiento de la naturalidad en el hombre, algo que le permite verse a sí mismo ${ }^{41}$. La intuición y contemplación estéticas suspenden toda racionalización de la Naturaleza y no tiene sentido ningún tipo de dominio sobre lo visibilizado sino el reconocimiento vívido de una ley y principios superiores a los que el hombre está sometido $0^{42}$. De tal forma, la experiencia de la belleza salvaje es modelo moral, afianza el temperamento ${ }^{43}$. La Naturaleza es buena, no en el sentido de la bondad propia de la moral cristiana ${ }^{44}$, sino en el sentido estéticopráctico; en ella nos podemos reencontrar como seres libres, y dar sentido a la destrucción, la carnicería y la muerte ${ }^{45}$ como parte activa de la creación, el respeto y la vida.

El valor de lo salvaje está en la conservación de la humanidad, es el nexo con la vitalidad primordial. La humanidad se ha centrado en superficialidad, en la lucha por lo aparente ${ }^{46}$; por lo mismo, el hombre debe recuperar la belleza salvaje ${ }^{47}$, la cual es la

37 "¿Qué importan las joyerías? No hay nada más hermoso que un copo de nieve 0 una gota de rocío terminados con la habilidad suprema del artista" (Dreiser; 1980: 69).

38 "El artista no puede apresurarse. La Tierra gira alrededor del sol con inconcebible rapidez y, sin embargo, el agua del lago no se altera por ello" (Dreiser; 1980: 182).

39 "Es monstruoso que uno se preocupe apenas por los árboles y en cambio se interese mucho en las columnas corintias" (Dreiser; 1980: 179).

40 "No hay una observación pura y objetiva, la esencia de lo que el escritor, sea poeta, filósofo o científico, tiene que referir es, simplemente, experiencia humana" (Dreiser; 1980: 79).

41 "Solo lo salvaje nos atrae" (Dreiser; 1980: 79).

42 ".... el hombre como individuo se relaciona con el resto de la Naturaleza" (Dreiser; 1980: 81).

43 "[...] en la Naturaleza más salvaje existe no solamente el material de la vida más cultivada y una especie de último resultado, sino también un refinamiento mayor que el que alcanza nunca el hombre" (Dreiser;1980: 81).

44 Es bien sabido que Thoreau detestaba la filantropía, las acciones nobles, la piedad, por tanto las instituciones sociales, la Iglesia, el Estado, la cruel economía capitalista, el esclavismo, la guerra, los prejuicios raciales, etc.

45 "[...] fui a buscar los restos de un cuerpo humano, una semana después de un naufragio y que habían sido arrojados a la playa [...] y allí yacían los restos, en cierto estado perfectamente inofensivo, en virtud de la escena que le rodeaba [...] el cadáver estaba solo con el mar, cuyo rugido profundo parecía dirigido a los oídos del muerto, [...] aquel cuerpo muerto poseía la playa como no podía poseerla ningún cuerpo vivo" (Dreiser;1980: 201).

46 "[...] la apariencia de riqueza, el vestido, el lujo, el carruaje son las únicas cosas que inspiran respeto. Quienes ceden ante ellas son verdaderos paganos que necesitan que les envíen misioneros" (D, p. 195).

47 "Fui a los bosques porque quería vivir deliberadamente, enfrentarme solo a los hechos esenciales de mi vida y ver si podía aprender lo que la vida tenía que enseñar, y para no descubrir, cuando tuviera que morir, que no había vivido. No quería vivir lo que no fuera la vida, pues vivir es caro, ni quería practicar 


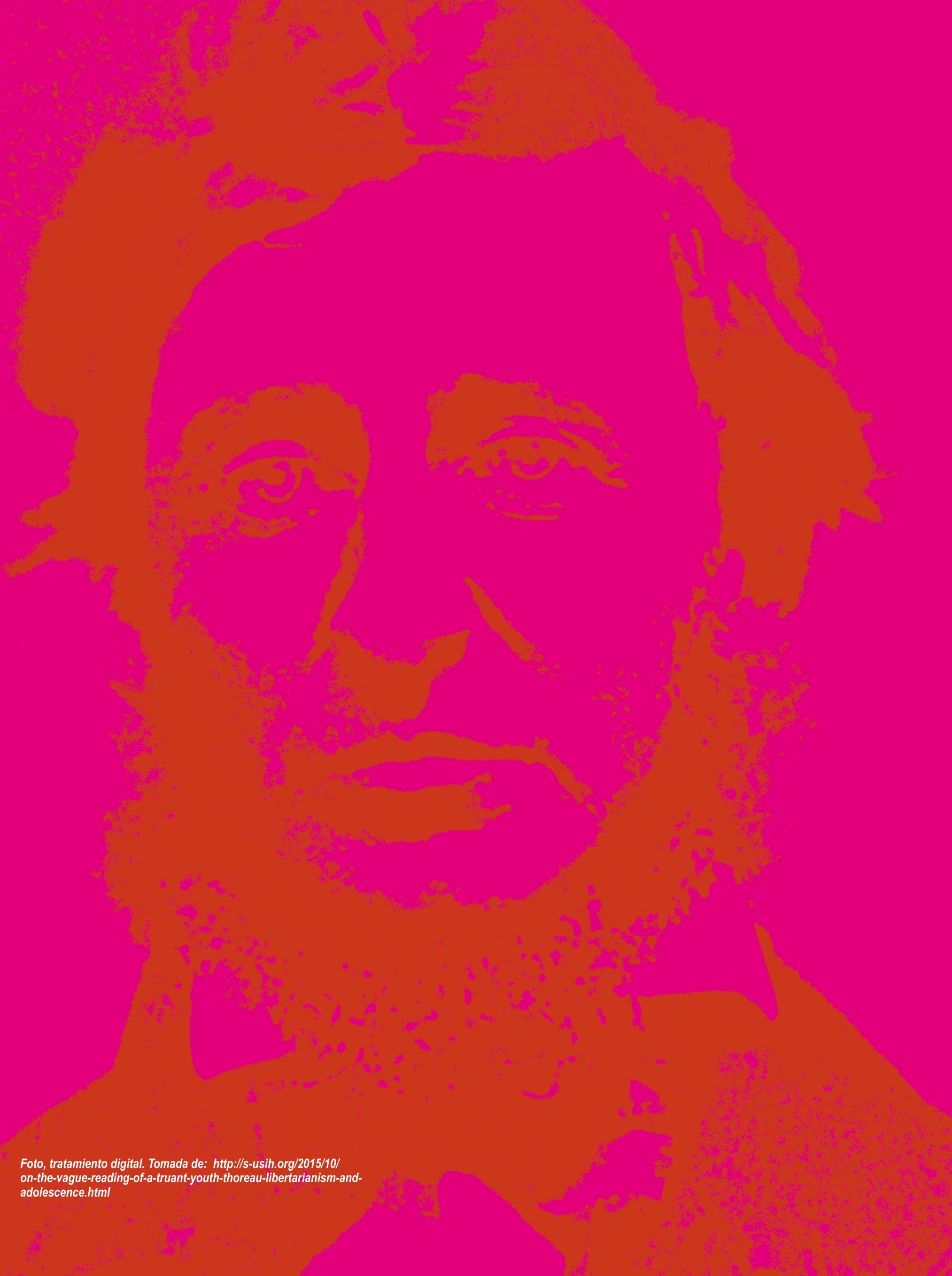


preservación del mundo, el oasis de la civilización y el modelo de la absoluta libertad ${ }^{48}$. En la experiencia de la belleza salvaje la austeridad de lo inmediato queda compensada por el esplendor de lo mediato, así no hay necesidad de dominar ni modificar el entorno; la mirada es inocente, la visión está desapegada de finalidades 0 apriorismos ${ }^{49}$. En ese sentido debe valorarse la vida animal ${ }^{50}$, la conservación de lo salvaje ${ }^{51}$, la Naturaleza en general. El progreso $0^{52}$, el urbanismo $0^{53}$, la propiedad de la tierra, en general, las mezquinas realizaciones humanas con la Naturaleza empobrecen al hombre ${ }^{54}$. De tal forma, al tratar la Naturaleza con acrecentado respeto, Thoreau se pone cerca de un ateísmo naturalista, de una ética antimaterialista ${ }^{55}$. Resulta cercano y lejano de Rousseau, no plantea un retorno utópico sino concreto a la Naturaleza. No está nada cerca del Romanticismo europeo, que asume lo bello natural como algo dado para el individuo cultivado y digno, y aunque renuncia a los artificios de la sociedad, no resulta ascético, sino que, por el contrario, su sensitivo amor por la belleza de la Naturaleza es un rechazo al desdén moderno por la vida misma, como en los cínicos. Thoreau buscaba encontrar en la Naturaleza algo superior a las pasiones, buscaba una forma de iluminar por qué el gusto por la belleza natural es la forma de dar sentido a la vida humana en el planeta.

la resignación a menos que fuera completamente necesario. Quería vivir con profundidad y absorber toda la médula de la vida, vivir de manera tan severa y espartana como para eliminar cuanto no fuera la vida" (Thoreau, 2005, p. 19). 48 "Quisiera hablar a favor de lo propio de la libertad absoluta y agreste, en contraposición a la libertad y cultura meramente civiles, considerar al ser humano un habitante, una parte integral de la Naturaleza, más que como un miembro de la sociedad" El texto dice: "quisiera hablar de la naturaleza de la libertad", entonces, en vista de nuestro objeto, y para evitar vaguedades, cambiamos la palabra "naturaleza -en minúscula-" que significaría propiedad o característica, por "lo propio de".

49 "Los hechos no deben ser más que el armazón de mis descripciones, deben ser material de la mitología que escribo; no deben ser hechos que ayuden a los hombres a hacer dinero y a los agricultores a labrar la tierra" (Dreiser; 1980: 181).

50 "He dado muerte a un animal con objeto de hacer estudios científicos pero no puedo excusarme a mí mismo por este asesinato, tales actos no están de acuerdo con la percepción poética" (Dreiser;1980: 196).

51 "[...] un río, con sus cascadas y sus vegas, un lago, una colina, una escollera o unas rocas aisladas, un bosque y árboles viejos que se alzan aisladamente. Esas cosas son hermosas; poseen una utilidad superior que nunca poseen los dólares y los centavos [...] si los habitantes fuesen prudentes conservarías esas cosas, aún a costa de un gasto de dinero considerable" (Dreiser; 1980: 177).

52 " $¡$ Qué poco nos interesan las invenciones más maravillosas de los tiempos modernos! Insultan a la Naturaleza. Cada máquina o cada aplicación particular de ella parece un pequeño ultraje a las leyes universales" ((Dreiser; 1980: 194).

53 "[...] para mí la esperanza y el futuro no están en las leyes ni en los campos cultivados, no en los pueblos ni en las ciudades, sino en los pantanos impenetrables y resquebrajantes" (Thoreau, 1998: 142).

54 "[... pobre cultura humana. Poco puede esperarse de una nación que agota el humus vegetal y se ve obligada a hacer abono con los huesos de sus padres" (Thoreau, 1998: 144).

55 "No es suficiente que me digas que trabajaste mucho para conseguir tu oro. También el diablo trabaja intensamente. El camino de la transgresión puede ser difícil de muchas maneras. El oro obtenido de ese modo no es igual que el sueldo de un trabajador honrado. Pero en la práctica, solo se percibe el hecho, no el principio, y se entra en esa dinámica. Hombres convertidos en demonios, y sin respetar los derechos de los demás en su sed de riqueza" (Dreiser; 1980: 192).

\section{Referencias}

Dreisser, T. (1980). El pensamiento vivo de Thoreau. L. Echávarri (trad.). Buenos Aires: Editorial Losada.

Thoreau, H. D. (1998). Caminar. Buenos Aires: Ardora Ediciones.

Thoreau, H. D. (2004). Desobediencia civil y otras propuestas. Buenos Aires: Longseller Ediciones.

Thoreau, H. D. (2005). Walden o la vida en los bosques. Buenos Aires: Editorial Cátedra.

Javier Guillermo Merchán-Basabe. Filósofo, Magíster en Historia y Teoría del Arte y la Arquitectura. Docente de la Universidad Pedagógica Nacional. Investigador en el área de Estética de la Naturaleza. Artista independiente.

jgmerchan@unal.edu.co

Artículo recibido en noviembre del 2016 y aceptado en enero del 2017 